\title{
Unsteady shock front waviness in shock- buffet of transonic aircraft
}

\author{
Razvan Marian Apetrei ${ }^{1 *}$, Vlad Ciobaca², Jose Luis Curiel-Sosa ${ }^{1}$ and Ning Qin ${ }^{1}$
}

\author{
* Correspondence: RMApetrei1@ \\ sheffield.ac.uk \\ 'Department of Mechanical \\ Engineering, The University of \\ Sheffield, Sheffield, UK \\ Full list of author information is \\ available at the end of the article
}

\begin{abstract}
The unsteady transonic aerodynamics of a wing-body configuration is investigated by solving the Unsteady Reynolds-averaged Navier-Stokes equations closed with the full Reynolds Stress Model. This work presents the prediction of flow field characteristics during deep shock-buffet penetration of a transport aircraftrepresentative geometry. Mach number of 0.85 , and Reynolds number of 5 million based on the mean chord, are selected to reproduce experimental test conditions that serve as validating datasets. The results obtained give information about both surface and flow field shock-buffet dynamics. An unsteady shock front is observed on the suction side of the wing which gives birth to the so-called buffet cells. Flow field characteristics are dominated by the presence of lambda-shaped shocks and fully separated boundary layer over a significant part of the wing.
\end{abstract}

Keywords: Aerodynamics, CFD, Shock-buffet

\section{Introduction}

The presence of unsteady shock wave/boundary layer interactions (SWBLI) in transonic flow was first reported in the 1940s together with photographs of shock oscillations about a low-drag transonic aerofoil [1]. Nowadays, the phenomenon, typically referred to as shock-buffet or transonic buffet, is a known cause of unfavourable aerodynamic and aeroelastic response in modern transport aircraft. It is one of the limiting factors when it comes to aircraft flight envelopes as strict buffet margins are required by certification bodies.

Early studies concerning shock-buffet revealed the effects of Mach number (M), Reynolds number (Re), and three-dimensionality on buffet onset and dynamics. A decrease in the incidence at which shock-buffet occurs was observed with an increase in $M$ as reported in [2-4]. It was not until recently that two buffet onset mechanisms were developed. Lee [5] proposed an acoustic wave propagation mechanism. A second, more recent shock-buffet mechanism was developed by Crouch et. al. [6], who argued that the shock-buffet onset is based on a global flow instability. Giannelis et. al. [7] show in their state-of-the-art review that both mechanisms received ample support from the research community. This alludes that there is still too much we do not understand about this phenomenon.

(c) The Author(s). 2020 Open Access This article is licensed under a Creative Commons Attribution 4.0 International License, which permits use, sharing, adaptation, distribution and reproduction in any medium or format, as long as you give appropriate credit to the original author(s) and the source, provide a link to the Creative Commons licence, and indicate if changes were made. The images or other third party material in this article are included in the article's Creative Commons licence, unless indicated otherwise in a credit line to the material. If material is not included in the article's Creative Commons licence and your intended use is not permitted by statutory regulation or exceeds the permitted use, you will need to obtain permission directly from the copyright holder. To view a copy of this licence, visit http://creativecommons.org/licenses/by/4.0/. 
With advancing technology, the use of Computational Fluid Dynamics (CFD) in shock-buffet prediction has increased substantially in the last two decades. The $2 \mathrm{D}$ experimental results for the OAT15A aerofoil [8] have been used for validation in a series of CFD studies in which the Unsteady Reynolds-averagedNavier-Stokes (URANS), Large Eddy Simulations (LES), and hybrid RANS-LES approaches have been applied [9-16]. The variation in results presented revealed that there is still an uncertainty in prediction of shock-buffet by means of URANS, particularly when closed with eddyviscosity-based turbulence models. CFD has also been successfully applied to shockbuffet prediction for 3D configurations. Iovnovich and Raveh [17], produced URANS results which show the effect of varying sweep and aspect ratio of rectangular wings on shock-buffet. They also coined the term of buffet cell which is now used to describe the spanwise extent and oscillation of the shock wave. The presence of these spanwise oscillations have since been observed in detail by Sugioka et. al. [18] in a transport aircraft-representative configuration.

A wing-body aircraft configuration was simulated in shock-buffet by Sartor and Timme [19, 20] using both URANS and Delayed Detached Eddy Simulations (DDES). Both approaches compared well with experiments. Recently, the NASA Common Research Model $(\mathrm{CRM})^{1}$, representative of modern wide-body aircraft, was used as a test bed and simulated using a Zonal DES approach [21-23]. The three studies which compare numerical results with experimental observations of Sugioka et. al. [18] and Koike et. al. [24] showed intricate shock-buffet dynamics and a qualitative comparison with experiments. Similar observations were presented by Ribeiro et. al. [25] who used the Lattice Boltzman Method (LBM). Timme [26] produced a shock-buffet onset prediction on the NASA CRM which was in good agreement with experiments. He also found evidences that reinforce Crouch's global instability shock-buffet onset mechanism. Still no efforts have been made to further characterise this phenomenon evolution with increase in flight angle of attack.

The current contribution introduces URANS-based simulations in the context of predicting shock-buffet dynamics on industrially-relevant aircraft configurations. A second-moment closure, the full Reynolds Stress Model (RSM), is selected as a turbulent closure for the URANS equations. RSM are considered to be part of an advanced class of turbulence models, not widely used due to their cost. However, in this case, the use of RSM is justified. Gianellis et. al. [15] found that RSM closures are more robust than typically used Spalart-Allmaras (SA) and Shear Stress Transport (SST) turbulence models for 2D shock-buffet prediction. Steady-state simulations by Apetrei et. al. [27] and many participants at the American Institute of Aeronautics and Astronautics CFD Drag Prediction Workshop ${ }^{2}$ (AIAA CFD DPW) found that for this particular test case, off-design flight predictions produced by closing the RANS equations with eddy-viscosity turbulence models can result in unphysical side-of-body separation [28].

Experimental campaigns of National Aeronautics and Space Administration (NASA) $[29,30]$ provide the base for validation of current results, including the decision on flight conditions. The observations from Japan Aerospace Exploration Agency (JAXA)

\footnotetext{
${ }^{1}$ https://commonresearchmodel.larc.nasa.gov/

${ }^{2}$ https://aiaa-dpw.larc.nasa.gov/
} 
wind tunnel campaigns $[18,24]$ are used for qualitative comparison, since the difference in flight Re and wind tunnel far field dynamic pressure resulted in different wing deformations, making a quantitative comparison not possible [31].

The remainder of the paper is structured as follows. Section 2 introduces the details of the numerical approach followed by a presentation and discussion of results in Section 3. Conclusions are then drawn in Section 4.

\section{Numerical approach}

\subsection{Geometry}

The wing-body NASA CRM [32] from the 6th AIAA CFD DPW, shown in Fig. 1, is used as a representative configuration of modern transport aircraft. For the current study, the geometry with applied wing deformations measured in the European Transonic Wind tunnel (ETW) at $4^{\circ}$ incidence is used to improve the quality of the comparison between numerical and wind tunnel data [33]. The full dimensions of the aircraft, given in Table 1, reveal its resemblance with today's wide-body jets.

Experimental data documenting the shock-buffet regime on this aircraft is available from Balakrishna and Acheson [30] for M and mean-chord Re of 0.85 and 5 million respectively. A smaller wind tunnel model was also experimentally tested in JAXA wind tunnels at lower mean-chord Re of 0.96 and 1.5 million. Although the latter wind tunnel campaign is more thorough, only a qualitative comparison can be produced since wind tunnel model deformations differ [31].

\subsection{Grid}

The grid used in this study has 17.5 million nodes and is produced using the commercial meshing tool ANSYS ICEM-CFD. The half-modelwing-body aircraft is placed at the centre of a semi-spherical fluid domain with a radius of 100 semispans. A multiblock structured grid is generated using quad and hex elements only in order to maintain mesh quality for viscous flow. The average $\mathrm{y}^{+}$value near wall is maintained to be lower than 1 as required by the implementation of the mathematical approach used [34]. This grid is a modified version from a previous study published by the authors which also includes a mesh-sensitivity analysis in line with AIAA CFD DPW guidelines [27]. The surface mesh and its features can be observed in Fig. 2.

\subsection{Solver}

The finite volume unstructured RANS solver DLR-Tau [35] is used in conjunction with the DLR-FlowSimulator [36] python interface. The convective fluxes are discretized using a second-order upwind scheme. Time-marching simulations are run with a LUSGSsemi-implicit time stepping scheme.

The RANS equations are closed with the SSG/LRR-g variation of the RSM model developed at DLR [34]. The model is a blend of the Speziale-Sarkar-Gatski (SSG) [37] and Launder-Reece-Rodi (LRR) [38] RSM turbulence models, with LRR-like behavior near-wall, and SSG-like behavior away from the wall [39]. The blending of the two models, originally in the SSG/LRR- $\omega$ model, has shown promising prediction of transonic aerodynamics in the DLR contributions to the AIAA CFD DPW [40, 41]. The current model solves one equation for each Reynolds stress component, and an 

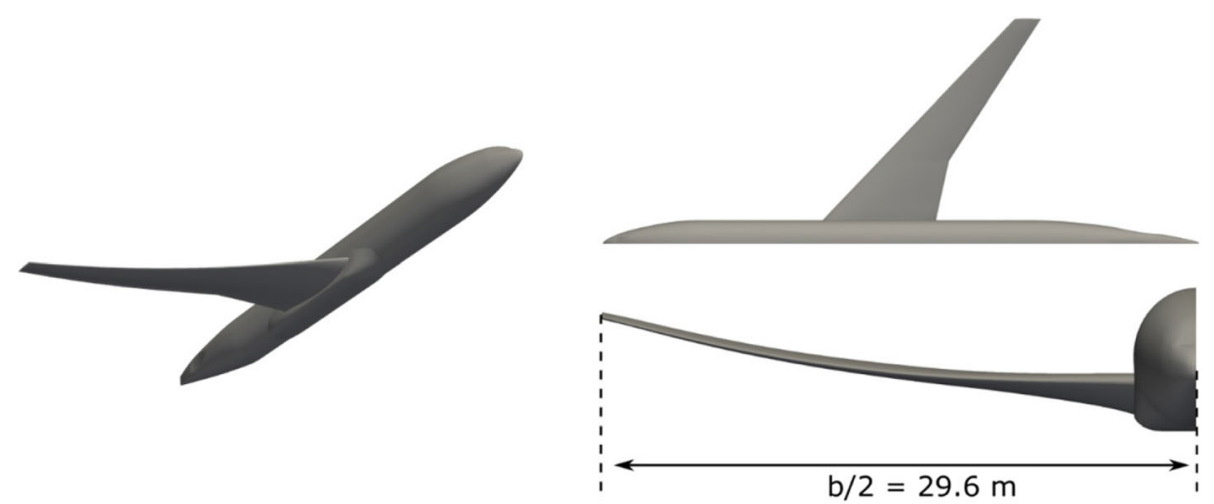

Fig. 1 The half model of the wing-body NASA CRM

additional equation for a turbulent scale. In this case, the turbulent scale is $g=\sqrt{1 / \omega^{2}}$, where $\omega$ is the specific rate of dissipation. The transformation to g solves numerical instabilities that the SSG/LRR- $\omega$ model had exhibited. This transformation did not have an impact on the accuracy of the results as shown in the work by Togiti and Eisfeld [34]. Initial simulations were also performed by closing the RANS equations with the SA-negative [42] turbulence model.

For the URANS computations, time-marching simulations were performed with a dual time-stepping approach with 100 inner iterations per physical time step. Solution convergence was monitored through the lift coefficient residual, which decreased by at least 6 orders of magnitude. A time step $\Delta t$ of $0.5 \mathrm{~ms}$ was chosen based on the physical convection times of an air molecule travelling over the mean chord at free stream velocity, and on the buffet frequencies expected. The total simulation time for all incidences was at least $1 \mathrm{~s}$. This resulted in at least 3 periods of the lowest frequency identified, and more than 15 of the highest. The time step sensitivity was evaluated by reducing $\Delta \mathrm{t}$ to $0.1 \mathrm{~ms}$ and comparing the unsteady buffet response.

\subsection{Computational test matrix}

For the present studies, the Mach number is maintained constant at 0.85 . Mean-chord Re of 5 million is set according to the NASA test. The incidence $\alpha$ was increased from $4^{\circ}$ to $5^{\circ}, 6$ and finally $6.5^{\circ}$. Steady-state results were obtained at $4^{\circ}$ incidence and will be presented in Section 3.1 as a means of validation. Unsteady time-marching simulations were restarted from semi-convergedsteady-state RANS results. Simulations at lower

Table 1 Geometrical dimensions of the NASA CRM CFD model

\begin{tabular}{ll}
\hline Dimension & - \\
Ref. Area & $389.76 \mathrm{~m}^{2}$ \\
Span & $59.226 \mathrm{~m}$ \\
Ref. Chord & $7.0005 \mathrm{~m}$ \\
Aspect Ratio & 9 \\
Taper Ratio & 0.275 \\
$\mathbf{2 5 \%}$ chord Sweep & $35.0^{\circ}$ \\
\hline
\end{tabular}




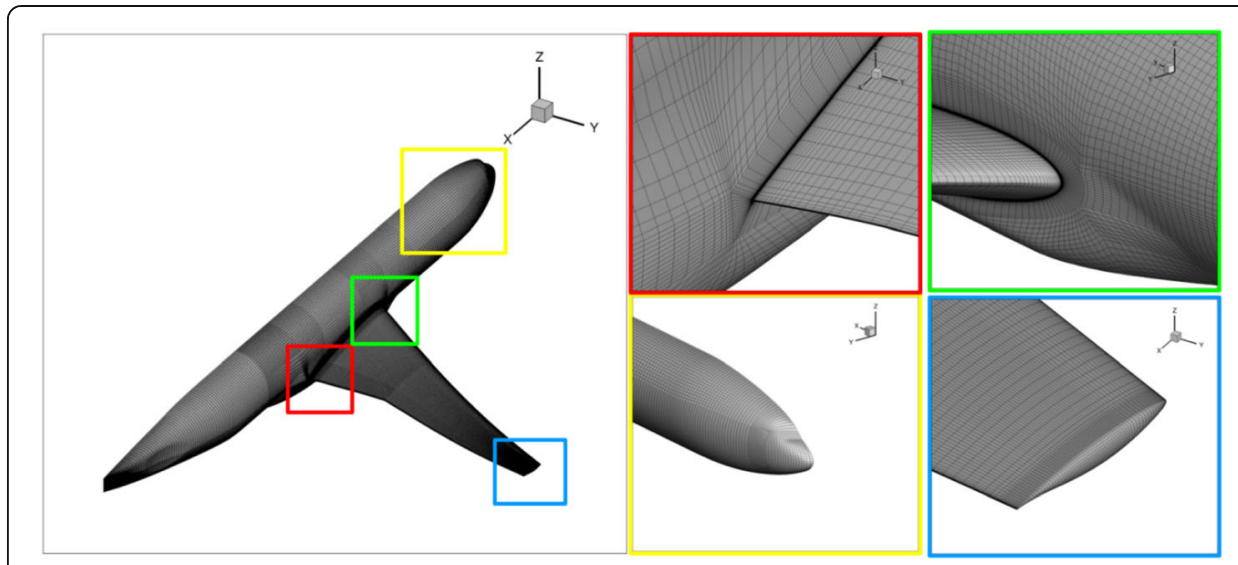

Fig. 2 Numerical grid and details

incidences are used as initialization for higher incidence ones (e.g. the results obtained at $\alpha=4^{\circ}$ are used to initialize the run for $\alpha=5^{\circ}$, and so on).

\section{Results}

\subsection{Validation}

\subsubsection{Steady RANS}

Steady-state results are produced for the incidence $\alpha=4^{\circ}$, a comparison of the SA-negative [42] and SSG/LRR-g RSM results with experimental observations is possible. Figure 3 presents pressure coefficient $\left(C_{P}\right)$ distributions extracted at 6 spanwise $(\eta)$ locations. Experimental results were reported by Rivers and Dittberner [29] and were obtained in the NASA wind tunnel facilities; they are easily accessible on the NASA CRM webpage.

In a first observation, we re-iterate that the SA-negative produces large discrepancies at the wing root $(\eta=0.131$ and 0.283$)$ due to an overpredicted side-of-body separation. This problem is eliminated by applying a Quadratic Constitutive Relationship (QCR) [43] which transforms the SA model into a non-linear one that is better able to capture the flow physics at the intersection between the wing and the fuselage. The benefits of using QCR for corner flows have been analysed more in depth by Dandois [44], to which the reader is referred.

Even after enabling QCR, the SSG/LRR-g-based results compare better with experiments than those obtained with the SA model. The two inboard slices $(\eta=0.131$ and 0.283$)$ are predicted to nearly identical as experiments. The computed results show stronger shocks being computed in the mid-wing region $(\eta=0.502$ and 0.727$)$, however the pressure recoveries downstream are well predicted. Towards the wing tip, CFD predicts higher loading, visible through a lower pressure plateau. At this incidence, Balakrishna and Acheson [30] reported small amplitude pressure fluctuations, however, the current simulations did not capture any unsteadiness after switching to URANS mode. It is currently believed that the discrepancies can be attributed to unsteadiness due to shock-buffet onset which is not modelled by our current mathematical and numerical approaches.

\subsubsection{Time step-sensitivity analysis}

Time step sensitivity is assessed via time-marching simulations at $M=0.85, \operatorname{Re}=5.0$ million, and $\alpha=6.0^{\circ}$. Simulated flow field data output at these conditions is used as 


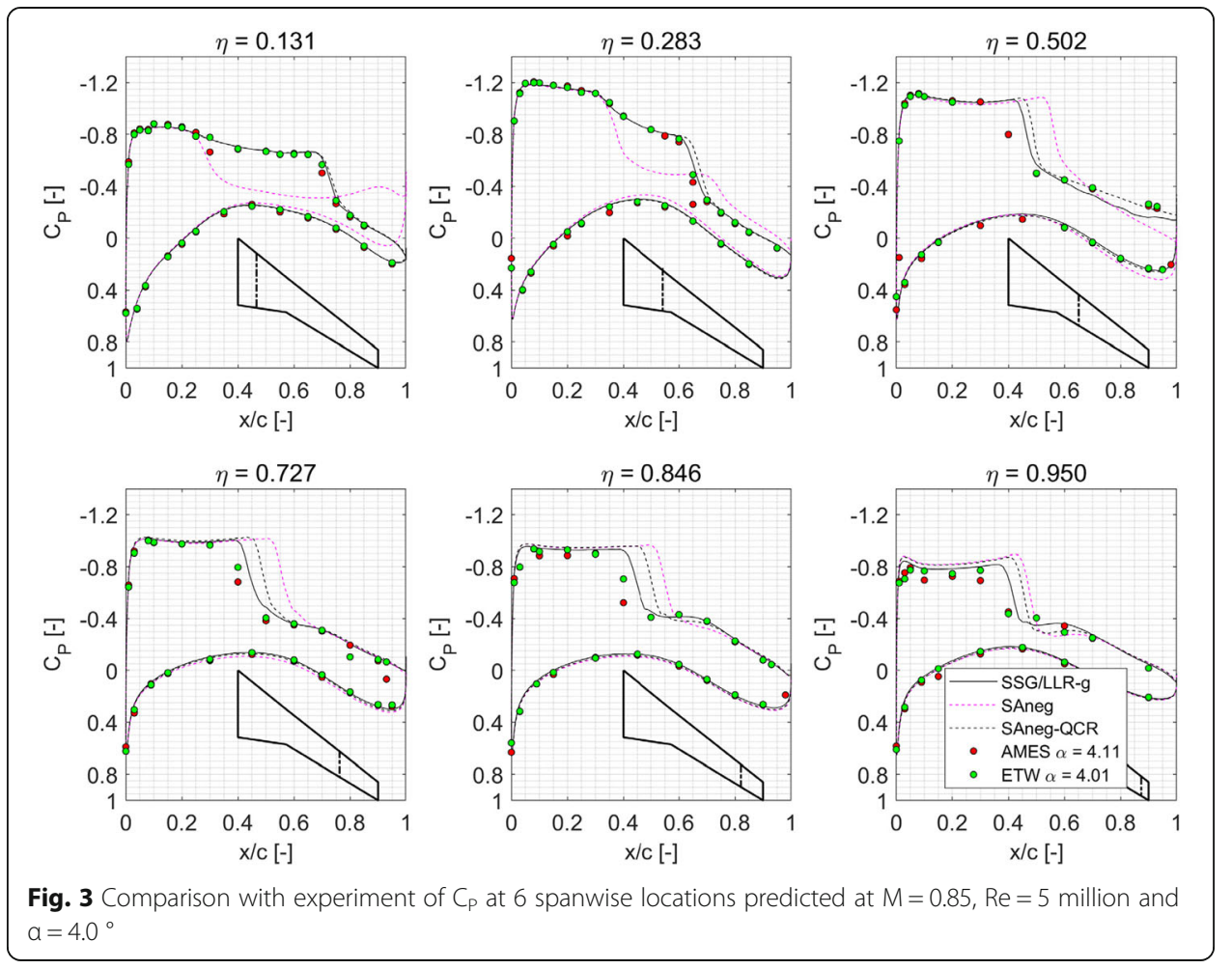

restart for a second simulation with a lower time step of $\Delta \mathrm{t}=0.1 \mathrm{~ms}$. A total of $0.2 \mathrm{~s}$ is simulated with this time step. The impact is assessed via sampled surface $C_{P}$. Figure 4 shows the extracted results at the spanwise locations $\eta=0.5$ and 0.6. On the left hand side, each line corresponds to the time-accurate $C_{P}$ recorded at a chordwise location. On the right hand side, the root mean square (RMS) of fluctuation, $C_{\text {Prms }}$ ' $=r m s$ $\left(C_{P \text {,mean }}-C_{P}\right)$, of those signals is given in comparison. The amplitude of oscillation is observed to vary locally but does not change the overall phenomenon. The location and frequency of maximum oscillation remain consistent. In a trade-off between computational power required and benefits of a smaller time step, it was decided that for this study, $\Delta t=0.5 \mathrm{~ms}$ was sufficient for the purpose of this study.

\subsection{Global forces and surface sampling}

Balakrishna and Acheson [30], measured buffet-onset on the CRM through small amplitude pressure/strain fluctuations at an incidence of $3^{\circ}$. A deep-buffet penetration regime, characterized by large amplitude pressure fluctuation followed as the angle of attack passed $5^{\circ}$. The characteristics of shock-buffet onset were previously numerically predicted by Timme [26]. This study focuses on the second regime, where shock-buffet is expected to be fully developed $\left(\alpha>5^{\circ}\right)$.

The computed lift coefficient, $\mathrm{C}_{\mathrm{L}}$ and comparison with the mean $\mathrm{C}_{\mathrm{L}}$ from experiments are given in Fig. 5 for incidences $\alpha=5,6$, and $6.5^{\circ}$.

Figure $5 \mathrm{a}$ shows the evolution of the time-accurate $\mathrm{C}_{\mathrm{L}}$ at all three incidences. The first $0.2-0.3 \mathrm{~s}$ of simulated time reveal a transition between the partly-converged RANS and URANS solutions. It indicates that the RANS solution is not the mean of the 

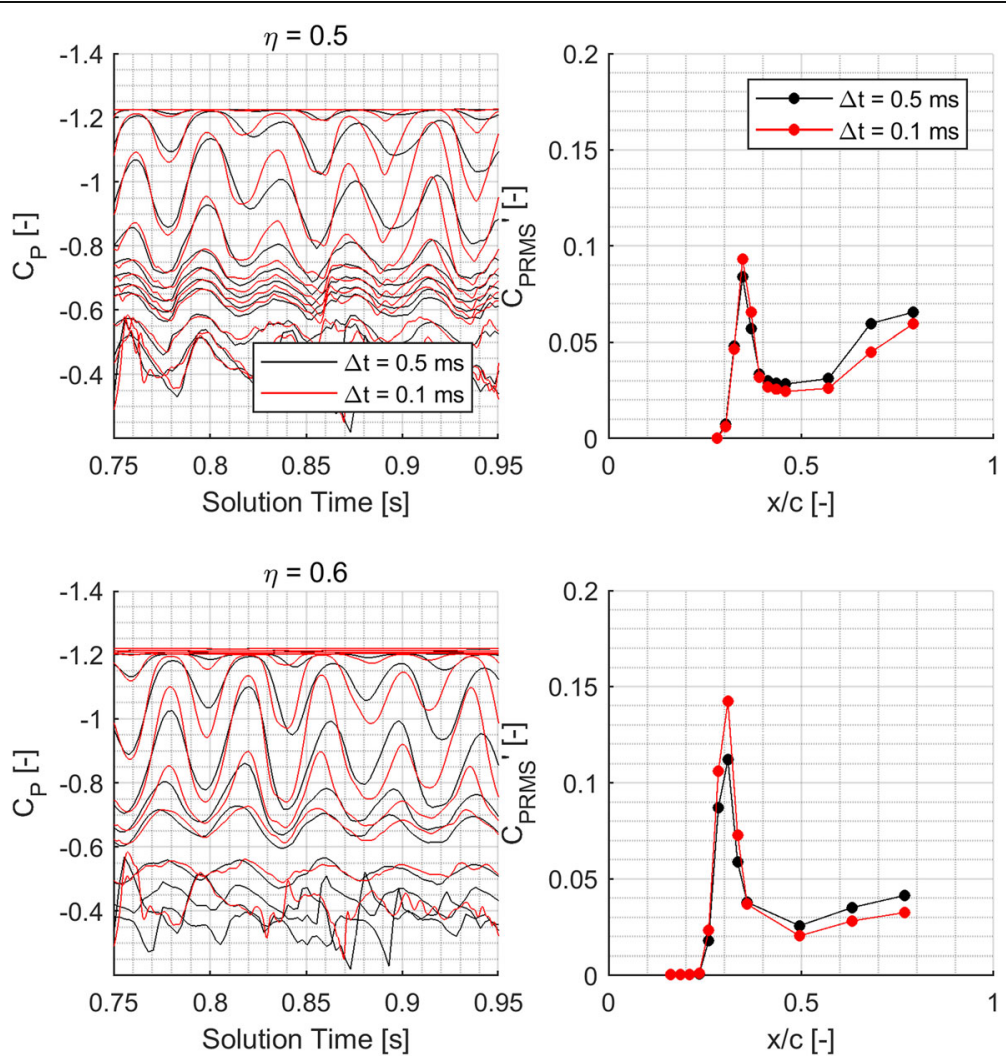

Fig. 4 Time step sensitivity analysis in the unsteady surface $C_{p}$ at $\eta=0.5 \& 0.6$. Each signal in the left hand side corresponds to an $\mathrm{x} / \mathrm{C}$ location

URANS one. At all three incidences, the RANS solution fluctuated around a lower $\mathrm{C}_{\mathrm{L}}$ than URANS. Secondly, the unsteadiness captured in Fig. 5a is not harmonic as previously seen for the RBC12 aircraft [19] or in 2D studies for the OAT15A aerofoil [916]. Although not shown here, the drag coefficient, $C_{D}$, and pitching moment coefficient, $C_{M}$, exhibit similar patterns. There is a clear unsteadiness in the global forces, however this is not a conclusive evidence of shock-buffet.

On the right hand side, Fig. $5 \mathrm{~b}$ gives the mean $\mathrm{C}_{\mathrm{L}}$ and RMS of fluctuation (error bars) in comparison with mean experimental values from NASA wind tunnel campaigns. The computed $\mathrm{C}_{\mathrm{L}}$ compares well at an incidence of $5^{\circ}$, however at higher incidence the values are over predicted by $1-2$ lift counts ( 1 lift count $=0.01$ in $C_{\mathrm{L}}$ ). The error bars, indicating $\mathrm{C}_{\mathrm{LRMS}}$ ' show that with an increase in incidence, the amplitude of fluctuation in $\mathrm{C}_{\mathrm{L}}$ increases too.

A better detection of shock-buffet is achieved by sampling surface pressure to identify the areas where flow unsteadiness is present. On-the-fly pressure probing is performed. The DLR-FlowSimulator python interface allows for the definition of 64 surface probes (see Fig. 6) placed at the location of the unsteady pressure transducers in the wind tunnel experiments $[18,24,30] . C_{P}$ is extracted every 5 timesteps resulting in an extraction frequency of $400 \mathrm{~Hz}$, equivalent to a non-dimensional Strouhal number, $\mathrm{St}=\mathrm{fc}_{\mathrm{mac}} / \mathrm{U}_{\infty}$, of 9.5; sufficient to collect 20 samples per period of oscillation at highest expected frequency based on previous experimental observations. The surface probes are inside the region of $\eta=0.5-0.731$ and local $x / c=0.16-0.8$, and benefit the current work by giving 


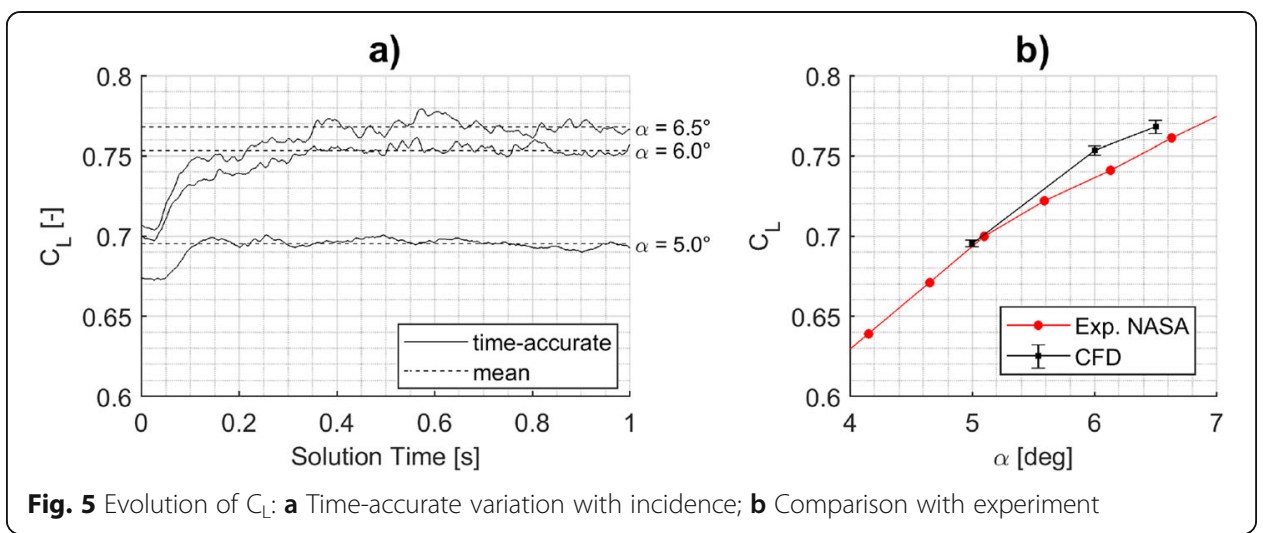

the opportunity to observe the evolution of the simulation without the need to postprocess/output large amounts of data.

Figures 7, 8, 9 shows the analysis of unsteady $C_{P}$ extracted at $\eta=0.6$ for $\alpha=5,6$, and

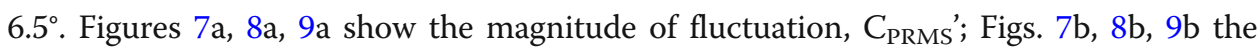
Power Spectral Distributions (PSD). Shock-buffet characteristics are identified. The magnitude of $\mathrm{C}_{\text {PRMS }}$ ' is observed to be maximum at the mean shock location (see Figs. 10 and 11). It increases in amplitude and spatial coverage as incidence is increased. At $\alpha=6$, and $6.5^{\circ}$, the PSD shows multiple frequencies between $\mathrm{St}=0.05-0.6$ present, within the range of shock-buffet phenomenon. One dominant frequency between $\mathrm{St}=0.5-0.6$ is also propagated downstream whereas lower St only present at the shock location. The St obtained compare reasonably well with the velocity-based Dynamic Mode Decomposition (DMD) by Ohmichi et. al. [23] who found, numerically, dominant modes at $\mathrm{St}=0.06$ and between $0.2-0.6$ when analysing shock-buffet response on the CRM at a lower Re. However, the high frequency fluctuation at $\mathrm{St}=0.5-$ 0.6 was not observed in experiments performed with this aircraft.

To conclude the surface analysis for shock-buffet detection, computed $C_{P}$ slices are presented at 6 spanwise locations against mean experimental data in Fig. 10. It is visible that at $\eta=0.727-0.846$ sections the shock location is predicted marginally more upstream than in the wind tunnel tests. The pressure sides, suction peaks and pressure recoveries downstream of the shock are overall well predicted. Starting with $\eta=0.397$, the timeaccurate $C_{P}$ reveals significant unsteadiness in the region downstream of the shock. In the mid-wing region of $\eta=0.502-0.603$, this unsteadiness is coupled with significant shock travel and a variation in trailing-edge loading on the pressure side of the wing. Outboard at, $\eta=0.727-0.95$, the unsteadiness reduces to mainly an oscillation of the shock.

\subsection{Shock-buffet dynamics}

Because shock-buffet data at current flight conditions and with current CRM configuration is limited, this section focuses on analyzing shock-buffet characteristics by concentrating on shock dynamics on the wing surface and inside the flow field. The results computed for $\alpha=6^{\circ}$ are presented herein. This paper comes accompanied with supplementary animations that help visualise flow unsteadiness. They are available on the Cambridge Journals and Sheffield Online Research Data (ORDA) repository webpages, DOI link available [45]. 


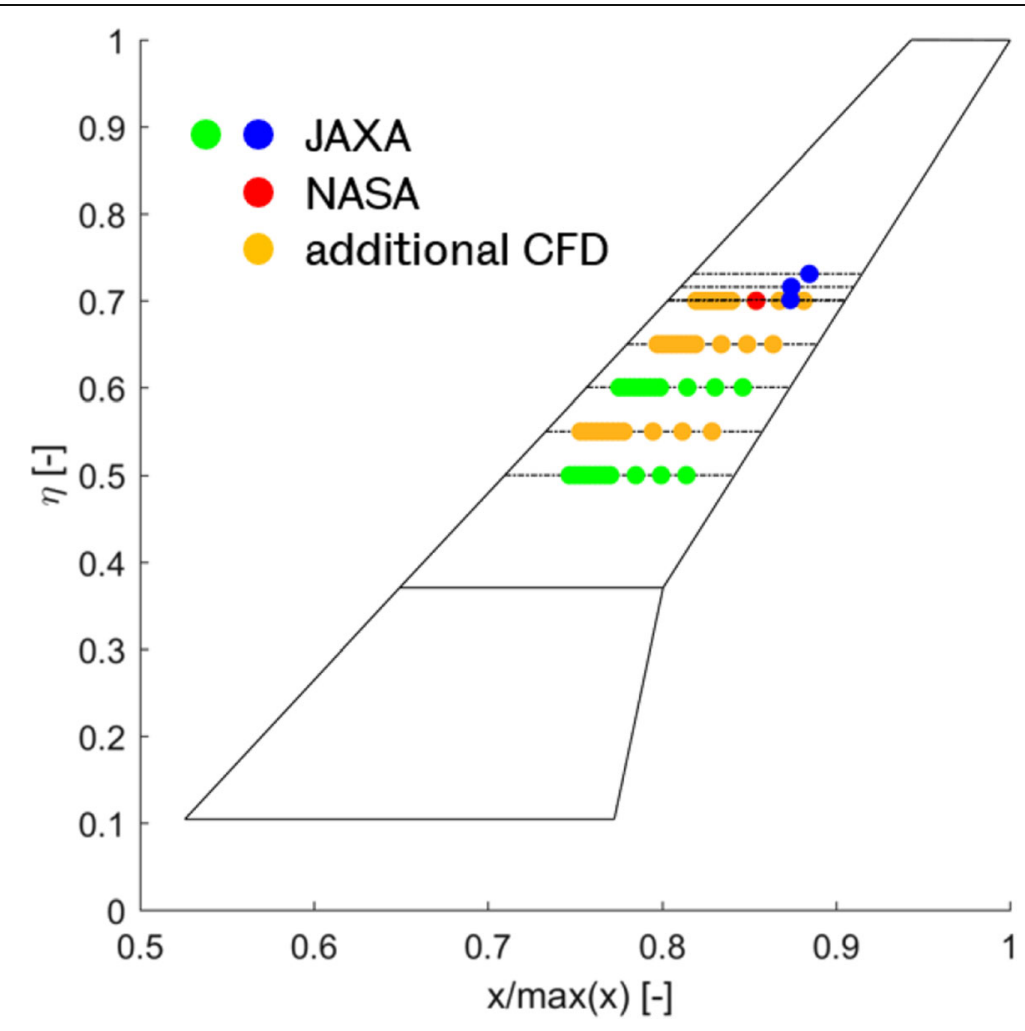

Fig. 6 Location of $C_{p}$ probes on the upper surface of the wing based on experiments from JAXA [18, 24] and NASA [30] plus additional ones included in CFD

Figure 11 gives contours of mean pressure coefficient and RMS of fluctuation on the upper side of the wing. A sharp pressure increase is observed across the shock, undoubtedly the cause of boundary layer separation. The $C_{\text {PRMS }}$ ' contours show that large amplitude fluctuations are concentrated at the shock location outboard of the wing trailing-edge break. Unsteadiness is also present downstream, in the region where shock-induced separation is present. Towards wing root and over the fuselage the fluctuations are negligible.

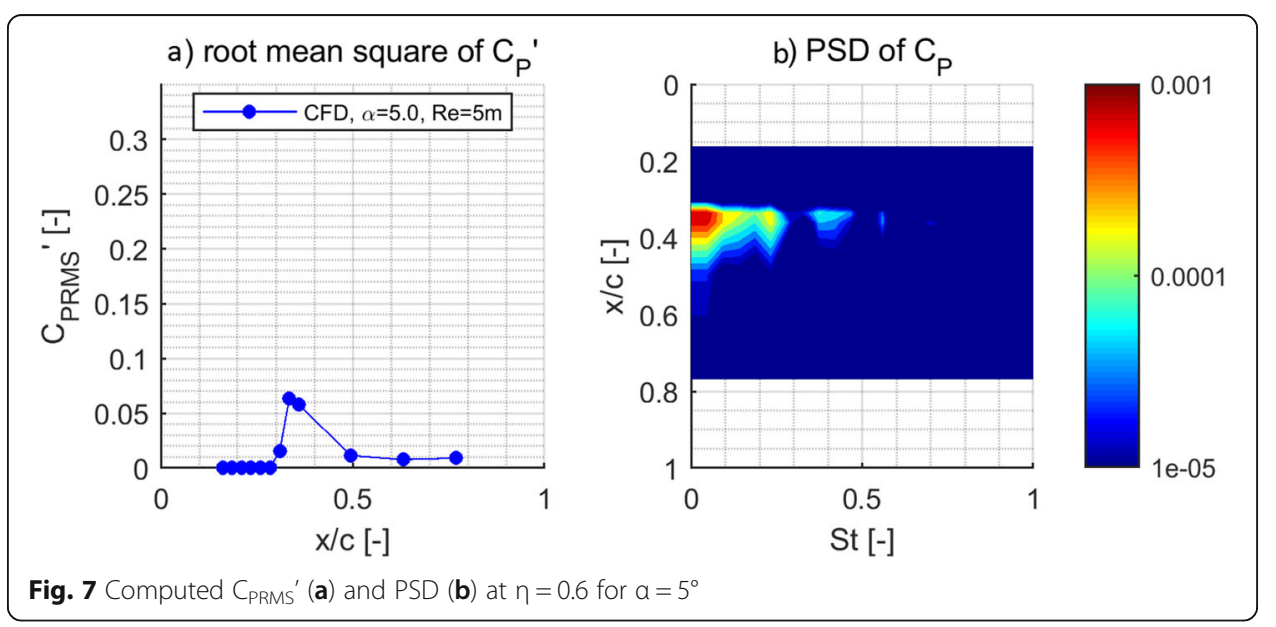




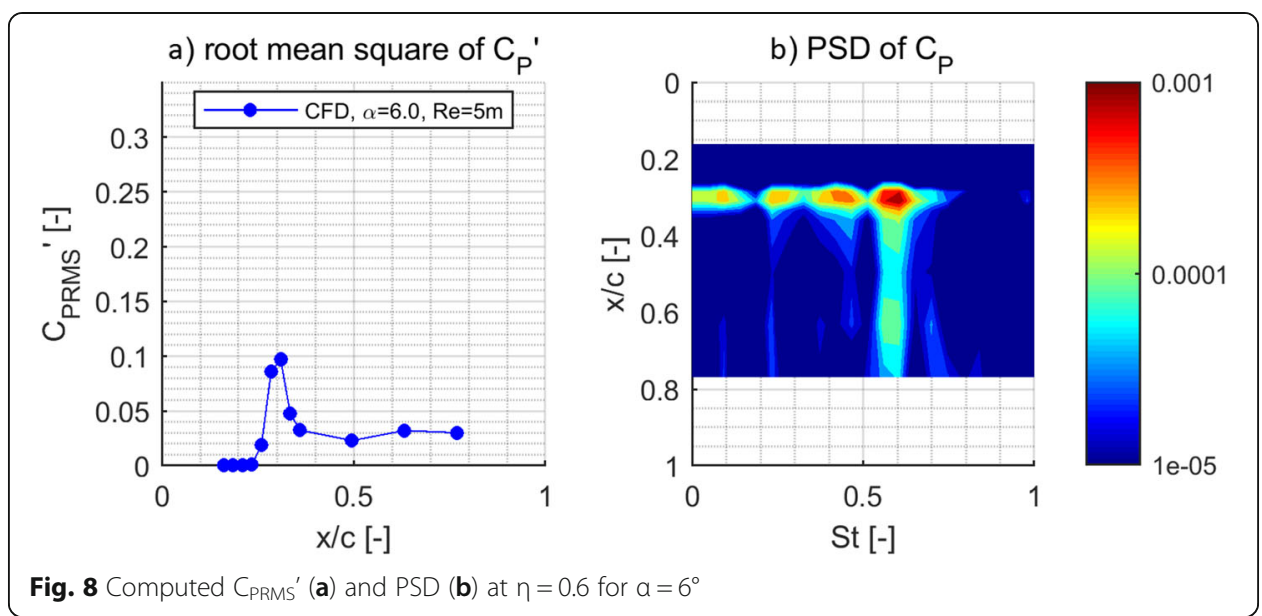

Time-accurate $C_{P}$ is not reported herein, however an animation is provided as supplementary material. It shows that the shock oscillates on the wing surface in a sinusoidal manner. To better visualize this oscillation, buffet cells contours are provided in Fig. 12. Contours of $C_{P}{ }^{\prime}=C_{P}-C_{P m e a n}$ of alternate colours indicate if the local shockposition is upstream $\left(+v e \mathrm{C}_{\mathrm{P}}{ }^{\prime}\right)$ or downstream $\left(-v e \mathrm{C}_{\mathrm{P}}{ }^{\prime}\right)$ when compared to the mean location. The computed buffet cells are qualitatively similar with the wind tunnel observations of Sugioka et. al. [18] who have experimentally tested the CRM at a lower Re. Figure 12 shows that each buffet cell travels towards the wingtip; a black * marks the most inboard buffet cell and aids the reader observe its travel in time. The distance between two buffet cells of same colour is then the wavelength of oscillation in the spanwise direction, $\lambda$, measured as 0.2 semispan. Knowing the frequency of oscillation which was identified previously in Fig. 8b St $=0.5-0.6$ then the convection speed of the shock, $\mathrm{U}_{\mathrm{C}}=\lambda \mathrm{f}$ can be approximated as 0.4 to 0.5 of the freestream velocity, $\mathrm{U}_{\infty}$.

The flow field output is analysed to determine the shock-buffet dynamics in the flow field. Figure 13 shows an instantaneous snapshot of the shock, extracted using the normal Mach number criteria developed by Lovely and Haimes [46]. The top view in Fig. 13b shows that the shock extends over the entire span of the wing. Inboard of the trailing-edge break, the top view of the shock-front shows that the main shock is

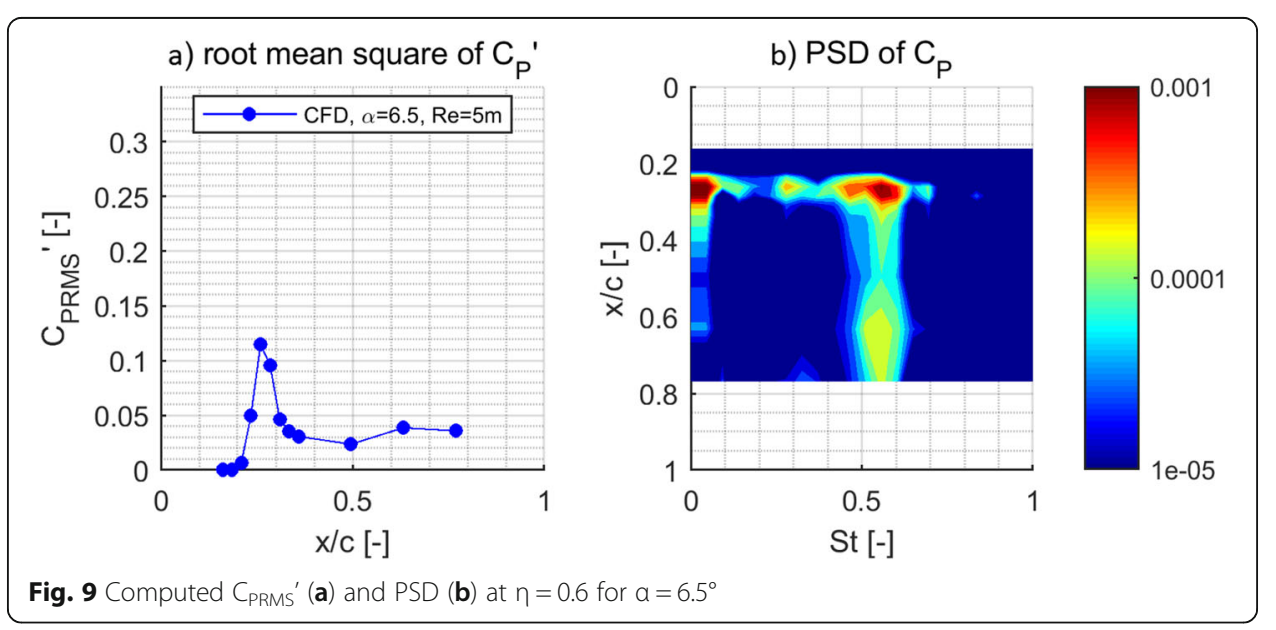




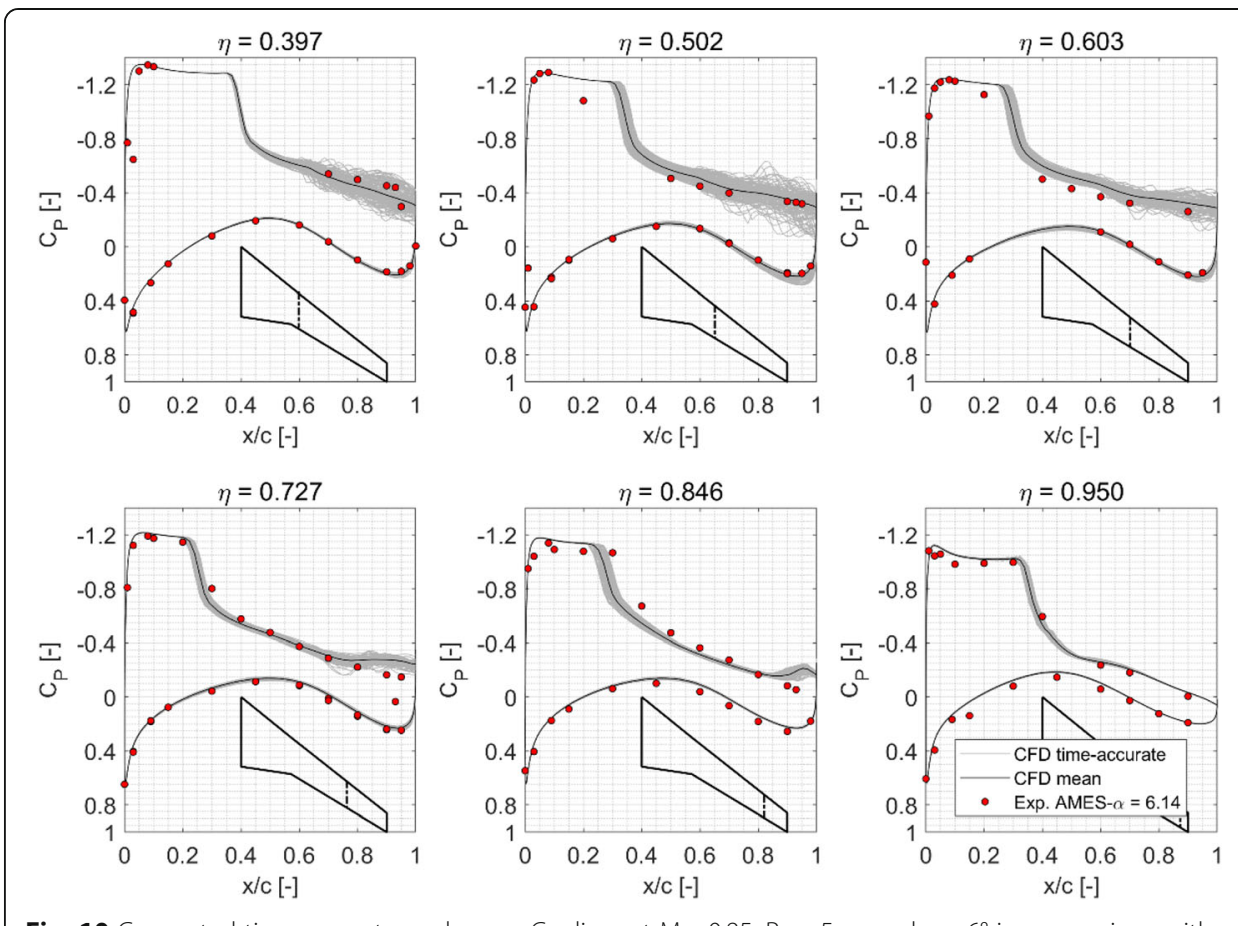

Fig. 10 Computed time-accurate, and mean $C_{p}$ slices at $M=0.85, R e=5 \mathrm{~m}$, and $a=6^{\circ}$ in comparison with experimental values

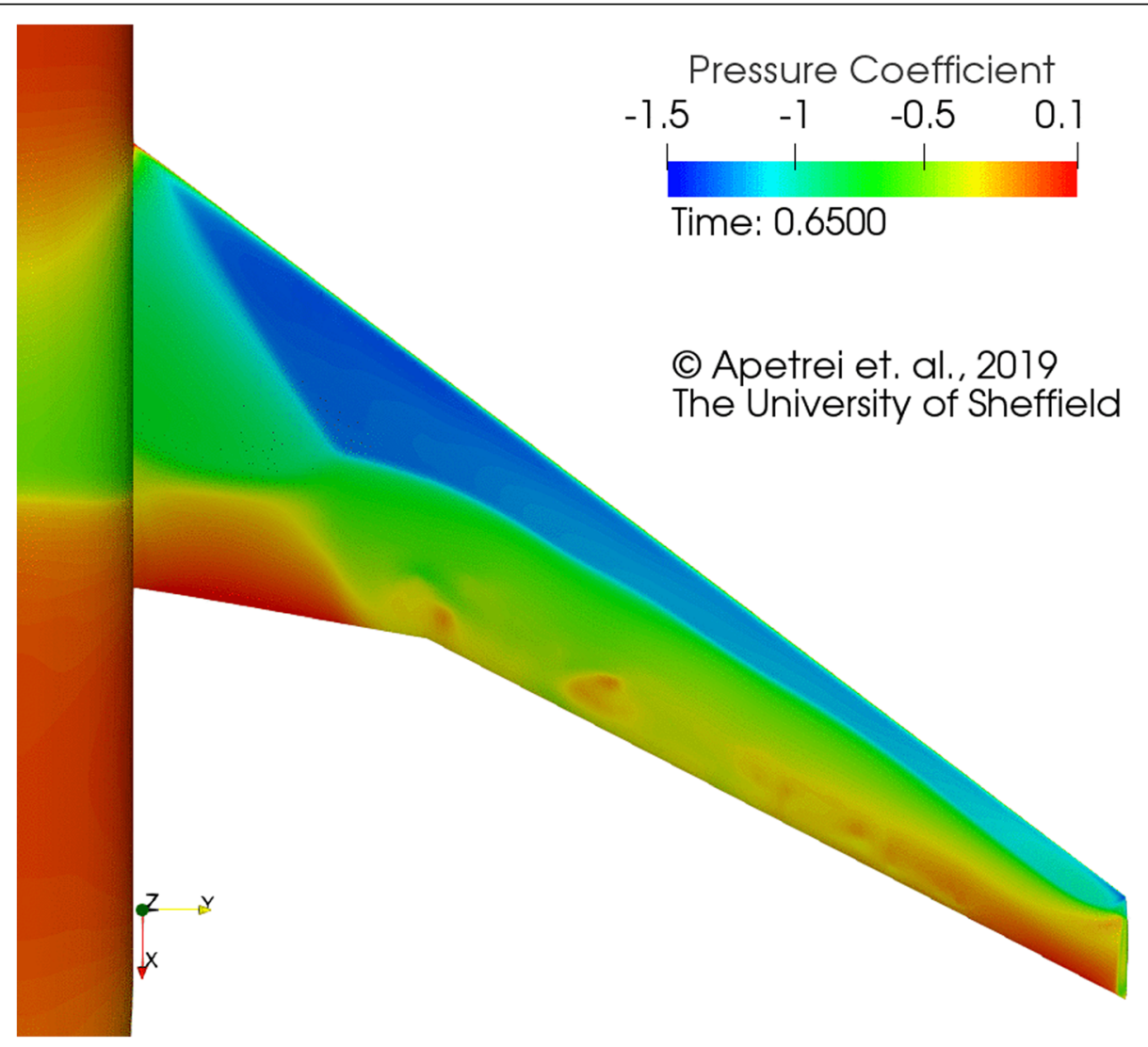

Fig. 11 Surface mean and RMS pressure contours at $M=0.85, R e=5 \mathrm{~m}$, and $a=6^{\circ}$ 


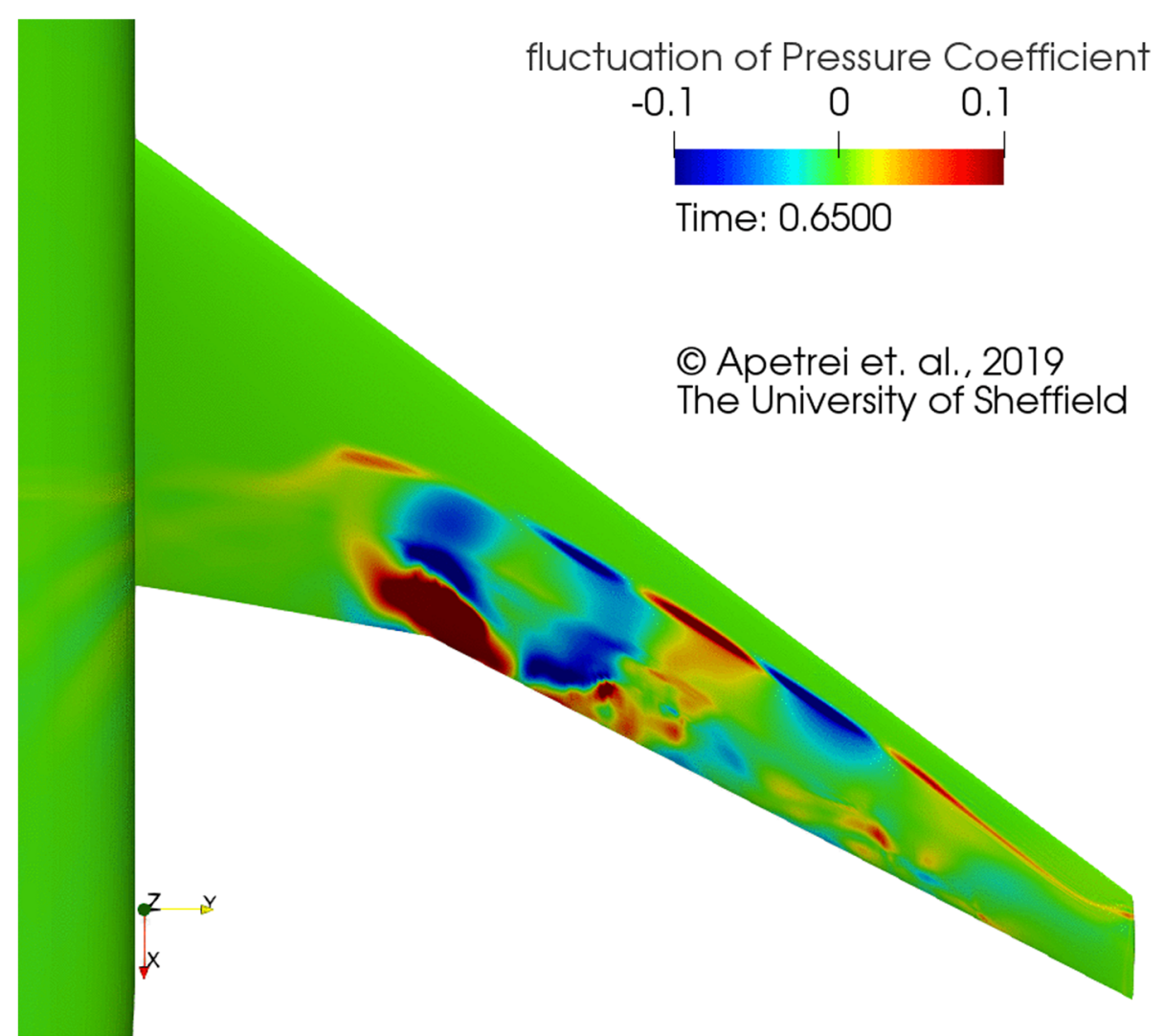

Fig. 12 Spanwise convection of the shock wave visualized through buffet cells at incidence $a=6^{\circ}$ over 1 period of highest St

preceded by a weaker one. From the top the shock front appears to be wide however this is because in the mid-wing region, the shock structure is $\lambda$-shaped near the wing surface, becoming normal only far away. This is visible in Fig. 14 where slices of the shock isosurface are plotted at $\eta$ between 0.283 and 0.95 . We appreciate that the shock extraction algorithm is not perfect, however the lambda shock structure near the wall is easily visible at $\eta=0.283$ and 0.397 . Close to the wingtip, at $\eta=0.95$ the shock is normal and remains as such in time.

An animated version of Fig. 14 is provided with the supplementary material. Figure 15 presents two snapshots superimposed. The shock unsteadiness in the flow field is in good agreement with what was observed on the surface via $C_{\text {PRMS }}$ ' and $\mathrm{C}_{\mathrm{P}}$ ' contours in Figs. 11 and 12. Insignificant shock displacement is present at $\eta=0.283$, the region where it is most prominent is $\eta=0.502-0.727$. The out-ofphase oscillation is also visible, in particular if the reader refers to Fig. 15b, c, d and e where local shocks are observed to oscillate in anti-phase. At $\mathrm{t}=1.22 \mathrm{~s}$, the shocks at $\eta=0.397$ and 0.603 are downstream, whereas at $\eta=0.502$ and 0.727 are upstream when compared to their locations at $\mathrm{t}=1.2 \mathrm{~s}$.

We now address the topic of shock-induced separation and its characteristics. In the 2D studies based on the OAT15A aerofoil, the boundary layer behind the shock presented a periodic separation \& reattachment behaviour. However, for this configuration, the boundary layer remains fully separated with complex periodic vortex 


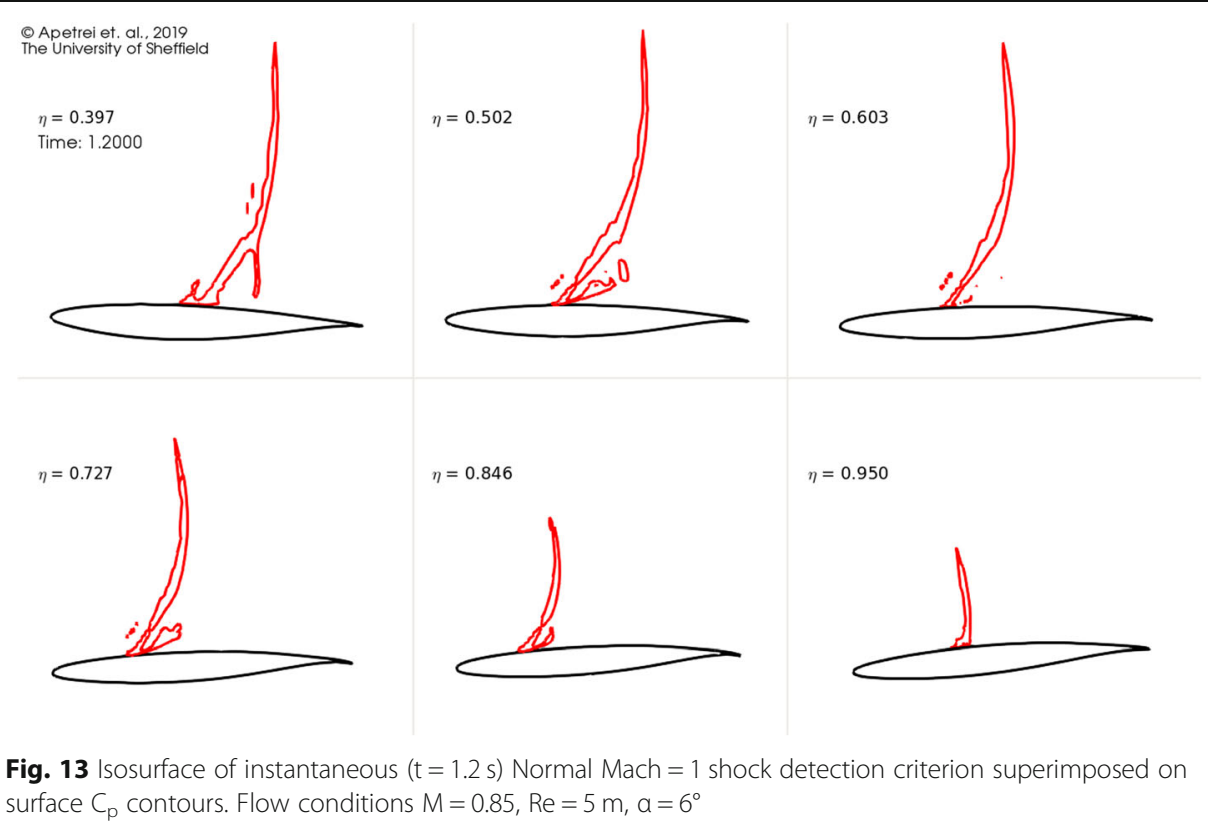

shedding spanning a significant portion of the wing. Figure 16 gives instantaneous isosurfaces of Q-criterion (the second invariant of the velocity gradient tensor) coloured by Mach number. An animated version of this is also included as supplementary material. The wingtip vortex and additionally another vortex at the trailing edge break are present in addition to successive vortical structures present in between.

\section{Conclusions}

The current work assessed the prediction of flow field characteristics during deep penetration into the shock-buffet regime of the NASA CRM aircraft. Mach number and

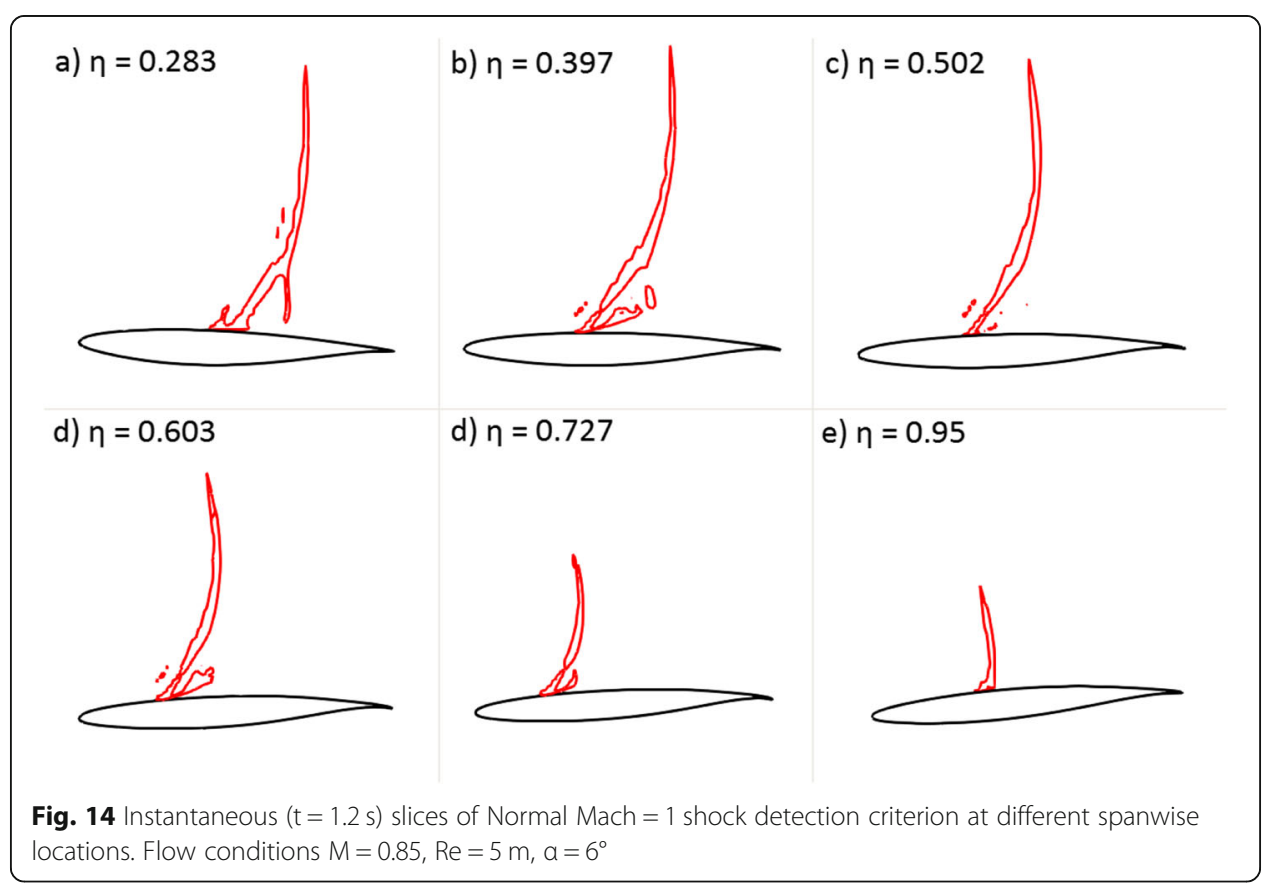




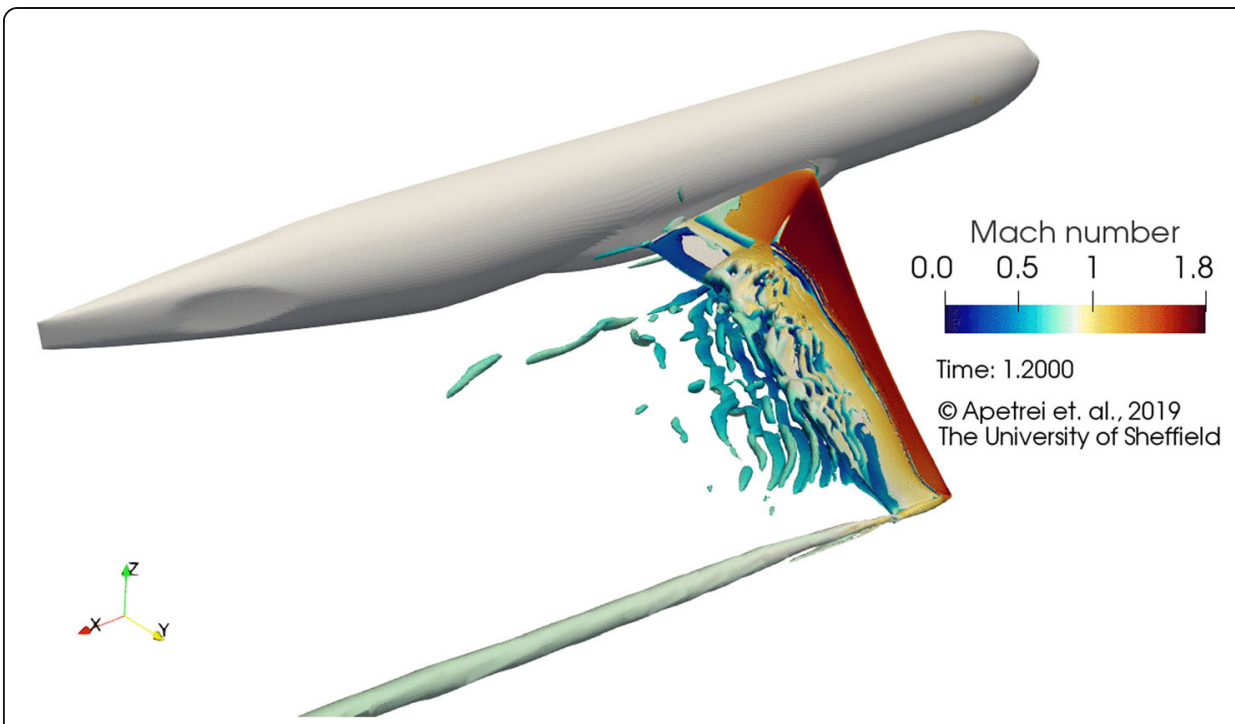

Fig. 15 Instantaneous slices of Normal Mach $=1$ shock detection criterion at different spanwise locations. Flow conditions $M=0.85, \operatorname{Re}=5 \mathrm{~m}, \mathrm{a}=6^{\circ}$

mean chord Re were set as 0.85 and 5 million respectively; incidence was varied between $\alpha=5$ and $6.5^{\circ}$. Simulations were produced by solving the URANS equations closed with a second moment closure. Validation of the results showed quantitative agreement with mean experimental data and compared well qualitatively with shockbuffet dynamics observed at lower Reynolds numbers.

Time-accurate surface pressure coefficients were extracted and used as on-theflyshock-buffet detection technique. The analysis of the signals revealed that high amplitude fluctuations, with multiple dominant frequencies between $\mathrm{St}=0.05$ and 0.6, were present at shock location; the frequencies were within the expected range of shockbuffet phenomenon. The surface shock-front was globally unsteady, exhibiting periodic patterns in the spanwise direction that gave birth to buffet cells. Flow field analysis,

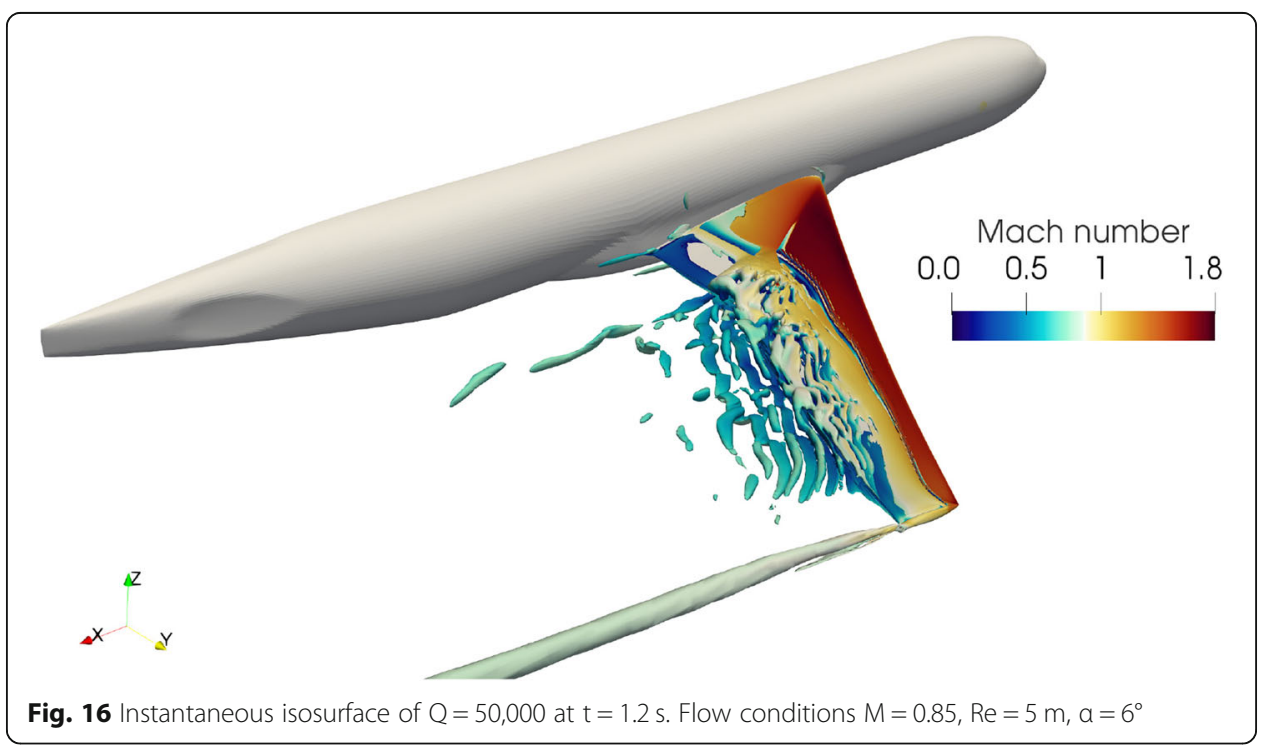


including the extraction of the shock surface by means of Normal Mach criterion provided a new insight into the flow field dynamics. The shock strength decreased from root to tip; it contained $\lambda$-shaped foot over a significant part of the wing. Timeaccurate snapshots showed how the buffet cells are reflected in the flow field. Locally the shock oscillation was out-of-phase between different spanwise locations.

Compared to previously reported results for other geometries, this configuration exhibited fully separated boundary-layer that did not reattach during the buffet cycle. Successive shedding of vortical structures were identified by means of Q-criterion isosurfaces.

\section{Nomenclature}

\section{Symbols}

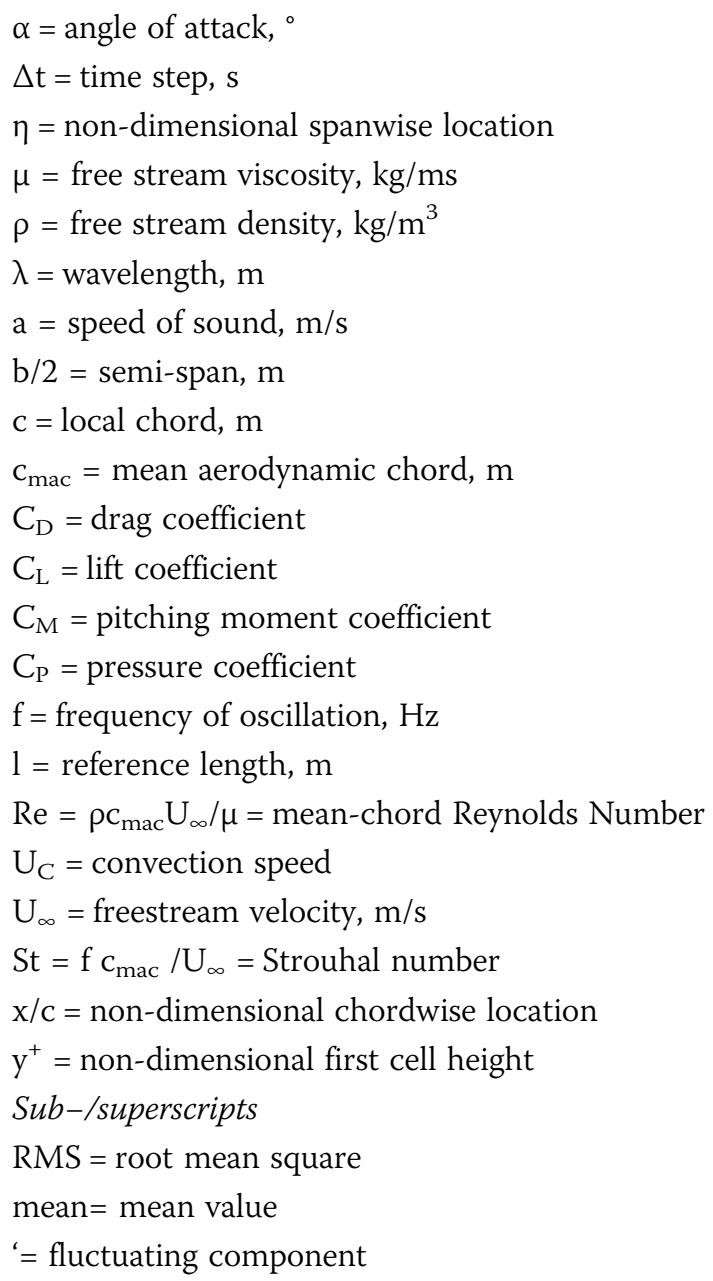

\section{Acknowledgements}

The authors would like to acknowledge the German Aerospace Center (DLR) for providing the TAU and FlowSimulator computational packages, the $C^{2} A^{2} S^{2} E^{2} H P C$ facilities, and Stefan Keye of DLR for his invaluable input on setting up the simulations presented in this paper. 


\section{Funding}

The authors would like to acknowledge the University of Sheffield for funding of the project through a PhD studentship to the first author. This project has also been supported through an additional funding received via the Postgraduate Researcher Experience Programme (PREP) from the same institution.

\section{Availability of data and materials}

Supplementary materials and data related to this publication is openly available on the Sheffield ORDA repository webpage under the following DOI: https://doi.org/10.15131/shef.data.8874989.

\section{Competing interests}

The authors declare that there are no competing interests.

\section{Author details}

${ }^{1}$ Department of Mechanical Engineering, The University of Sheffield, Sheffield, UK. ${ }^{2} D L R$, Institute of Aerodynamics and Flow Technology, Braunschweig, Germany.

Received: 19 December 2019 Accepted: 2 April 2020

Published online: 23 April 2020

\section{References}

1. Hilton FW, Fowler RG (1947) Photographs of Shock Wave Movement. National Physics Laboratory R\&M 2692

2. McDevitt JB, Levy LL Jr, Deiwert GS (1976) Transonic flow about a circular-arc airfoil. AlAA J 14(5):606-613. https://doi. org/10.2514/3.61402

3. Seegmiller HL, Marvin JG, Levy LL Jr (1978) Steady and unsteady transonic flow. AIAA J 16(12):1262-1270. https://doi. org/10.2514/3.61042

4. Roos F (1985) The buffeting pressure field of a high-aspect-ratio swept wing. In: Proceedings of 18th fluid dynamics and plasmadynamics and lasers conference, fluid dynamics and co-located conferences. AlAA, Cincinnati. https://doi.org/10. 2514/6.1985-1609

5. Lee BHK (1990) Oscillatory shock motion caused by transonic shock boundary-layer interaction. AIAA J 28(5):942-944. https://doi.org/10.2514/3.25144

6. Crouch JD, Garbaruk A, Magidov D, Travin A (2009) Origin of transonic buffet on aerofoils. J Fluid Mech 628:357-369. https://doi.org/10.1017/S0022112009006673

7. Giannelis NF, Vio GA, Levinski O (2017) A review of recent developments in the understanding of transonic shock buffet. Prog Aerosp Sci 92:39-84. https://doi.org/10.1016/j.paerosci.2017.05.004

8. Jacquin L, Molton P, Deck S, Maury B, Souvelant D (2009) Experimental study of shock oscillation over a transonic supercritical profile. AIAA J 47(9):1985-1994. https://doi.org/10.2514/1.30190

9. Deck S (2005) Numerical simulation of transonic buffet over a supercritical airfoil. AIAA J 43(7):1556-1566. https://doi. org/10.2514/1.9885

10. Szubert D, Asproulias I, Grossi F, Duvigneau R, Hoarau Y, Braza M (2016) Numerical study of the turbulent transonic interaction and transition location effect involving optimisation around a supercritical aerofoil. Eur J Mech B Fluids 55(2): 380-393. https://doi.org/10.1016/j.euromechflu.2015.09.007

11. Grossi F, Braza M, Hoarau Y (2014) Prediction of transonic buffet by delayed detached-eddy simulation. AIAA J 52(10): 2300-2312. https://doi.org/10.2514/1.J052873

12. Thiery $\mathrm{M}$, Coustols $\mathrm{E}$ (2006) Numerical prediction of shock induced oscillations over a $2 \mathrm{D}$ airfoil: influence of turbulence modelling and test section walls. Int J Heat Fluid Flow 27(4):661-670. https://doi.org/10.1016/j.j.jheatfluidflow.2006.02.013

13. Huang J, Xiao Z, Liu J, Fu S (2012) Simulation of shock wave buffet and its suppression on an OAT15A supercritical airfoil by IDDES. Sci China Phys Mech Astronomy 55(2):260-271. https://doi.org/10.1007/s11433-011-4601-9

14. Fukushima Y, Kawai S (2018) Wall-modelled large-eddy simulation of transonic airfoil buffet at high Reynolds number. AIAA J 56(6):2372-2388. https://doi.org/10.2514/1.J056537

15. Giannelis NF, Levinski O, Vio GA (2018) Influence of Mach number and angle of attack on the two-dimensional transonic buffet phenomenon. Aerosp Sci Technol 78(6):89-101. https://doi.org/10.1016/j.ast.2018.03.045

16. Apetrei RM, Curiel-Sosa JL, Qin N (2018) Prediction of unsteady transonic buffeting using the SU2 open-source code. In: Paper presented at $7^{\text {th }}$ European conference on computational fluid dynamics. ECCOMMAS, Glasgow 2018

17. lovnovich M, Raveh DE (2015) Numerical study of shock buffet on three-dimensional wings. AlAA J 53(2):449-463. https://doi.org/10.2514/1.J053201

18. Sugioka Y, Koike S, Nakakita K, Numata D, Nonomura T, Asai K (2018) Experimental analysis of transonic buffet on a 3D swept wing using fast-response pressure-sensitive paint. Exp Fluids 59(108):1-20. https://doi.org/10.1007/s00348-0182565-5

19. Sartor F, Timme $S$ (2016) Mach number effects on buffeting flow on a half wing-body configuration. Int J Numerical Methods Heat Fluid Flow 26(7):2066-2080. https://doi.org/10.1108/HFF-07-2015-0283

20. Sartor F, Timme S (2017) Delayed detached-eddy simulation of shock buffet on half wing-body configuration. AIAA J 55(4):1230-1240. https://doi.org/10.2514/1.J055186

21. Hashimoto A, Ishida T, Aoyama T, Ohmichi Y, Yamamoto T, Hayashi K (2018) Current Progress in unsteady transonic buffet simulation with unstructured grid CFD code. In: Proceedings of 2018 AIAA aerospace sciences meeting. AIAA, Kissimmee. https://doi.org/10.2514/6.2018-0788

22. Ishida T, Hashimoto A, Ohmichi Y, Aoyama T, Takekawa K (2017) Transonic buffet simulation over NASA-CRM by unsteady FaSTAR code. In: Proceedings of $55^{\text {th }}$ AIAA aerospace sciences meeting. AIAA, Grapevine, 2017. https://doi.org/ $10.2514 / 6.2017-0494$

23. Ohmichi Y, Ishida T, Hashimoto A (2018) Modal decomposition analysis of three-dimensional transonic buffet phenomenon on a swept wing. AlAA J 56(10):3938-3950. https://doi.org/10.2514/1.j056855 
24. Koike S, Ueno M, Nakakita K, Hashimoto A (2016) Unsteady pressure measurement of transonic buffet on NASA common research model. In: Proceedings of 34th AIAA applied aerodynamics conference. AIAA AVIATION Forum, AIAA, Washington, D.C. https://doi.org/10.2514/6.2016-4044

25. Ribeiro AF, Konig B, Singh D, Fares E, Zhang R, Gopalakrishnan P, Jammalamadaka A, Li Y, Chen H (2017) Buffet simulations with a lattice-Boltzmann based transonic solver. In: Proceedings of $55^{\text {th }}$ AIAA aerospace sciences meeting. AIAA SciTech, AIAA, Grapevine. https://doi.org/10.2514/6.2017-1438

26. Timme S (2019) Global shock buffet instability on NASA common research model. In: Proceedings of AIAA Scitech 2019 Forum. AIAA, San Diego. https://doi.org/10.2514/6.2019-0037

27. Apetrei RM, Curiel-Sosa JL, Qin N (2019) Using the Reynolds stress turbulence model to predict shock-induced separation on the common research model. J Aircr 56(2):583-590. https://doi.org/10.2514/1.C034968

28. Tinoco EN, Brodersen O, Keye S, Laflin K (2017) Summary of data from the sixth AIAA CFD drag prediction workshop: CRM cases 2 to 5. In: Proceedings of $55^{\text {th }}$ AIAA aerospace sciences meeting, AIAA SciTech, AIAA, Grapevine. https://doi. org/10.2514/6.2017-1208

29. Rivers MB, Dittberner A (2011) Experimental investigations of the NASA common research model in the NASA Langley National Transonic Facility and NASA Ames 11-Ft transonic wind tunnel. In: Proceedings of $49^{\text {th }}$ aerospace sciences meeting including the new horizons forum and aerospace exposition. AIAA, Orlando. https://doi.org/10.2514/6.20111126

30. Balakrishna S, Acheson M (2011) Analysis of NASA common research model dynamic data. In: Proceedings of 49th AIAA aerospace sciences meeting including the new horizons forum and aerospace exposition. AIAA, Orlando. https://doi. org/10.2514/6.2011-1127

31. Ueno M, Kohzai M, Koga S, Kato H, Nakakita K, Sudani N, Nakamura Y (2015) Normalization of wind-tunnel data for NASA common research model. J Aircr 52(5):1535-1549. https://doi.org/10.2514/1.C032989

32. Vassberg J, Dehaan M, Rivers M, Wahls R (2008) Development of a common research model for applied CFD validation studies. In: Proceedings of 26th AIAA applied aerodynamics conference. AIAA, Honolulu. https://doi.org/10.2514/6.20086919

33. Keye S, Brodersen O, Rivers MB (2014) Investigation of Aeroelastic effects on the NASA common research model. J Aircr 51(4):1323-1330. https://doi.org/10.2514/1.C032598

34. Togiti $\bigvee$, Eisfeld B (2015) Assessment of g-equation formulation for a second-moment Reynolds stress turbulence model. In: Proceedings of 22nd AIAA computational fluid dynamics conference. AIAA AVIATION Forum, AIAA, Dallas. https://doi. org/10.2514/6.2015-2925

35. Schwamborn D, Gerhold T, Heinrich R (2006) The DLR-TAU-code: Recent Applications in Research and Industry. In: Proceedings of ECCOMAS CFD 2006. Egmond aan Zee

36. Meinel M, Einarsson G (2010) The FlowSimulator framework for massively parallel CFD applications. In: PARA 2010 conference: state of the art in scientific and parallel computing. University of Iceland, Reykjavik

37. Speziale CG, Sarkar S, Gatski TB (1991) Modelling the pressure-strain correlation of turbulence: an invariant dynamical systems approach. J Fluid Mech 227(6):245-272. https://doi.org/10.1017/S0022112091000101

38. Launder BE, Reece GJ, Rodi W (1975) Progress in the development of a Reynolds-stress turbulence closure. J Fluid Mech 68(3):537-566. https://doi.org/10.1017/S0022112075001814

39. Eisfeld B. (2004) Implementation of Reynolds stress models into the DLR-FLOWer code, DLR-Interner Bericht. 124-2004/ $31,67 \mathrm{~S}$

40. Brodersen O, Crippa S, Eisfeld B, Keye S, Geisbauer S (2014) DLR results from the fourth AIAA computational fluid dynamics drag prediction workshop. J Aircr 51(4):1135-1148. https://doi.org/10.2514/1.C031533

41. Keye S, Togiti VK, Brodersen OP (2017) DLR results of the sixth AIAA computational fluid dynamics drag prediction workshop. In: Proceedings of 35th AIAA applied aerodynamics conference. AIAA AVIATION Forum, AIAA, Denver. https:// doi.org/10.2514/6.2017-4232

42. Allmaras SR, Johnson FT, Spalart PR (2012) Modifications and clarifications for the implementation of the SpalartAllmaras turbulence model. In: Proceedings of seventh international conference on computational fluid dynamics. Big Island, Hawaii

43. Spalart PR (2000) Strategies for turbulence modelling and simulations. Int J Heat Fluid Flow 21(3):252-263. https://doi. org/10.1016/S0142-727X(00)00007-2

44. Dandois J (2014) Improvement of corner flow prediction using the quadratic constitutive relation. AIAA J 52(12):27952806. https://doi.org/10.2514/1.J052976

45. Apetrei RM, Ciobaca V, Curiel-Sosa JL, Qin N (2019) DATA: Unsteady Shock Front Waviness in Shock-Buffet of the Common Research Model, ORDA. The University of Sheffield. https://doi.org/10.15131/shef.data.8874989

46. Lovely D, Haimes R (1999) Shock detection from computational fluid dynamics results. In: Proceedings of $14^{\text {th }}$ computational fluid dynamics conference. AIAA, Norfolk. https://doi.org/10.2514/6.1999-3285

\section{Publisher's Note}

Springer Nature remains neutral with regard to jurisdictional claims in published maps and institutional affiliations. 